\title{
PERFORMANCES DE GÊNERO NO QUOTIDIANO DE UMA DELEGACIA DA INFÂNCIA E JUVENTUDE: NOTAS DE UMA PESQUISA QUALITATIVA
}

\author{
Camila Silva Nicácioi \\ Júlia Silva Vidalii \\ Mariana Ferreira da Silvaiii \\ Hugo Ribeiro Lanzaiv
}

\section{RESUMO}

Com o presente trabalho, buscamos compreender como as normas de gênero e a heteronormatividade impactam no acautelamento e regulação dos corpos de jovens autores de ato infracional. O trabalho foi desenvolvido a partir dos principais resultados encontrados em pesquisa qualitativa realizada no interior de um órgão multi-institucional composto, entre outros, por órgãos do sistema de justiça e de segurança pública no estado de Minas Gerais. A partir da metodologia da observação participante e da realização de entrevistas, foi possível identificar as dinâmicas de produção e reprodução de desigualdades de gênero no fluxo do atendimento a adolescentes em um centro de atendimento da infância e da juventude nacional. Identificamos que tais dinâmicas se mostraram suscetíveis de reger também a relação entre os profissionais que trabalham naquele espaço, segundo a lógica da hierarquia, do estereótipo e da contenção de comportamentos divergentes da heteronormatividade.

PALAVRAS-CHAVE: gênero; infância e juventude; pesquisa qualitativa.

\footnotetext{
' Universidade Federal de Minas Gerais (UFMG), Belo Horizonte, MG, Brasil, ORCID; ii Universidade Federal de Minas Gerais (UFMG), Belo Horizonte, MG, Brasil, ORCID; iii Universidade Federal de Minas Gerais (UFMG), Belo Horizonte, MG, Brasil, ORCID; Iv Universidade Federal de Minas Gerais (UFMG), Belo Horizonte, MG, Brasil, ORCID.
} 


\title{
GENDER PERFORMANCE IN THE DAILY LIFE OF A JUVENILE JUSTICE POLICE STATION: NOTES FROM A QUALITATIVE RESEARCH
}

\author{
Camila Silva Nicácio \\ Júlia Silva Vidal \\ Mariana Ferreira da Silva \\ Hugo Ribeiro Lanza
}

\begin{abstract}
In this paper, we seek to understand how gender norms and heteronormativity impact the custody and regulation of the bodies of young people in "conflict with the law". The work was developed based on the main results found in qualitative research carried out within a multi-institutional body composed, among others, by bodies of the justice system and the public security in the state of Minas Gerais. Based on the methodology of participant observation and interviews, it was possible to identify the dynamics of production and reproduction of gender inequalities in the flow of care for adolescents at a domestic Juvenile Justice assistance center. Under the queer theory, we found out that such dynamics were also capable of governing the relationship between the professionals working in that context, according to the logic of hierarchy, stereotype and containment of behaviors diverging with heteronormativity.
\end{abstract}

KEYWORDS: gender; childhood and youth; qualitative research. 


\section{INTRODUÇÃO}

A complexa relação entre gênero e sexualidade no que toca à infância e juventude têm ocupado as preocupações de teóricos nos mais diversos campos do conhecimento e gestores de variados serviços públicos. No que concerne aos sistemas socioeducativo e de justiça da infância e juventude, tal intersecção merece aprofundamento, pois aponta para cenários de intensas violências. Motivada por relatos de violação de direitos humanos dentro do sistema de justiça da infância e juventude do estado de Minas Gerais, a Clínica de Direitos Humanos da Universidade Federal de Minas Gerais (CdH/UFMG) realizou a pesquisa Gênero e sexualidade no sistema socioeducativo, com vistas à compreensão do papel/efeito das normas de gênero e da heteronormatividade no acautelamento e regulação dos corpos de jovens em autores de ato infracional. O projeto recebeu parecer do Comitê de Ética em Pesquisa do Departamento de Direito do Trabalho da UFMG.

No âmbito da referida pesquisa, investigamos as dinâmicas de produção e reprodução das desigualdades de gênero a partir da teoria queer, e da compreensão das normas de gênero como performatividade em uma estrutura que é considerada como a "porta de entrada" do Sistema de Justiça Infanto-juvenil, especificamente a partir do fluxo de jovens em uma delegacia anexa a um centro de atendimento da infância e da juventude, órgão responsável pelo acolhimento e processamento das demandas no campo infracional.

A metodologia estabelecida para tal abordagem foi a de observação participante, elaboração de caderno de campo, com posterior análise do material escrito, discussão em grupo, bem como realização de entrevistas semiestruturadas com determinados atores atuantes naquele espaço.

Contamos restituir neste trabalho os principais elementos do que foi encontrado, a partir de três seções assim detalhadas: método e incursão no campo da delegacia de Polícia Civil (2), e análises a partir dos dados primários coletados em campo (3), seguidas de algumas conclusões preliminares (4). 


\section{DELEGACIA DE ORIENTAÇÃO E PROTEÇÃO À CRIANÇA E AO ADOLESCENTE DA POLÍCIA CIVIL: MÉTODO E INCURSÃO NO CAMPO}

A trajetória inicial do adolescente apreendido em flagrante pela prática de ato infracional começa nas garagens do edifício pela chegada do jovem dentro da viatura. O estacionamento divide espaço com três alojamentos, utilizados para a retenção de adolescentes acautelados aguardando audiência ou para repouso dos que já foram liberados, mas que precisam esperar por alguém para buscá-los. Subindo as escadas, chegamos ao andar térreo do edifício, que reúne salas da Polícia Militar e Civil, Núcleo de Encaminhamento e Serviço de Emissão de Identidade. É na sala da Polícia Militar em que formalmente se iniciam os procedimentos relativos à apuração da infração supostamente cometida pelo adolescente, a partir da lavratura do Registro de Evento de Defesa Social (REDS) e consequente inserção formal de seus dados no sistema. De lá, em não necessitando de atendimento hospitalar, o adolescente é encaminhado para a Polícia Civil, encarregada da lavratura do auto de apreensão ou termo circunstanciado, contato com o responsável legal do adolescente para que compareça à instituição, coleta de depoimento e oitiva de testemunhas. Por fim, o adolescente é direcionado à audiência preliminar, "a partir da qual são adotadas as seguintes medidas, isolada ou cumulativamente: arquivamento; concessão de remissão extintiva, como forma de exclusão do processo; aplicação de medida protetiva (art. 101 do ECA); oferecimento de representação (denúncia) oral pelo Ministério Público cumulada com a aplicação de uma das medidas socioeducativas (...)" (SILVA, 2010, p. 89).

Dentro desse fluxo, o primeiro local selecionado para ser observado em nossa pesquisa foi o departamento de Inspetoria da Polícia Civil, haja vista ser um ambiente que compõe a porta de entrada do sistema de segurança e justiça, por onde todos os jovens apreendidos pela Polícia Militar circulam, sendo também um dos primeiros espaços por onde passam. O campo da Polícia Civil foi um espaço onde pudemos observar, ao longo de 8 semanas, o quotidiano do ofício dos policiais, como são as organizações e relações de trabalho. Tomamos nota de como os policiais interagiam entre si, como lidavam com suas obrigações, mas também 
observamos como eles se relacionavam com os jovens atendidos. A partir da observação participante, pudemos nos inserir na rotina do trabalho na Inspetoria, de modo que a forma com a qual nos relacionamos com os policiais e como eles liam e entendiam nossos corpos naquele espaço também se mostrou importante para nossas análises.

A partir da nossa inserção na rotina do trabalho na Inspetoria, pudemos observar os modos pelos quais as normas de gênero e sexualidade operam naquele espaço. Pensando a pesquisa a partir da teoria queer, buscamos compreender as dinâmicas das normas de gênero e sexualidade na organização das relações sociais na instituição. Norma, nessa perspectiva, se relaciona com o ato de performar ou agir na realidade, que controla nossa experiência, ao mesmo tempo que garante nossa existência e funda uma realidade dentre outras tantas possíveis.

Assim, "agir de acordo com uma mulher/homem é pôr em funcionamento um conjunto de verdades que se acredita estarem fundamentadas na natureza" (BENTO, 2006, p. 93). Gênero, portanto, é uma expressão, um efeito de dominação que instala um regime, retira a historicidade e a contingência das concepções de masculino e feminino. Contudo, as instituições, inseridas na sociedade, produzem e reproduzem a norma, assim como os processos sociais constroem hierarquias sexuais e normalizam comportamentos (MISKOLCl, 2009), dessa forma, objetivamos entender como eles se dão e como engendram performances de gênero em uma Inspetoria da Polícia Civil.

A compreensão do cotidiano do ofício dos profissionais e agentes que trabalham na delegacia da Polícia Civil, as dinâmicas do fluxo de jovens acautelados e a relação entre os agentes e os jovens, e os agentes entre si, demandou da equipe o estabelecimento de um contato mais frequente e próximo com o campo. Não foi por outro motivo que a observação participante foi escolhida como método de análise, pois pressupõe a imersão no campo, encorajando "os pesquisadores a mergulharem nas atividades do dia a dia das pessoas as quais eles tentam entender" (MAY, 2004, p. 175). Partindo do pressuposto que o conhecimento também é pautado pela experiência e pela vivência pessoal direta com os eventos 
e fenômenos a serem analisados, sua construção é um processo que envolve a participação nas relações sociais em questão.

Desse modo, a observação participante é um instrumento metodológico qualitativo que permite a compreensão da apropriação do mundo pelos sujeitos e os aspectos subjetivos de seus modos de se relacionarem. Entendemos a observação participante como uma ferramenta que possibilita a compreensão das dinâmicas do espaço, havendo uma produção, e não coleta, dos dados. Segundo May (2004), o pesquisador que utiliza essa metodologia não se impõe no campo, ele se insere na realidade material, participando ativamente do mundo social e das dinâmicas a serem observadas. Por um período, os pesquisadores participam da vida quotidiana de uma comunidade ou instituição, observando os comportamentos dos sujeitos, suas interações e como eles constroem seus relacionamentos (GOLDENBERG, 2004). Na observação participante,

o observador, no caso, fica em relação direta com seus interlocutores no espaço social da pesquisa, na medida do possível, participando da vida social deles no seu cenário cultural, mas com a finalidade de colher dados e compreender o contexto sob sua observação e, sem dúvida, modifica esse contexto, pois interfere nele, assim como é modificado pessoalmente. (MINAYO, 2009, p. 76)

O pesquisador, na metodologia de observação participante, é um sujeito ativo, que se relaciona com o espaço/tempo/sujeito pesquisados. Não há pretensões de neutralidade, já que a própria interação do pesquisador com os sujeitos envolvidos na pesquisa é parcial. Cada pesquisador, no momento que tem seu corpo inserido no espaço, terá observações, apreensões, e relações distintas e diversas com os sujeitos que circulam e vivem a realidade em questão. Não há, portanto, objetos de pesquisa, mas situações, relações e dinâmicas as quais se busca apreender. Com esse instrumento de pesquisa, não buscamos respostas ou resoluções a questões estabelecidas: pelo contrário, objetivamos problematizar, levantar reflexões e identificar elementos da realidade social em questão. 
Na observação participante, as experiências dos pesquisadores são centrais. Nesse sentido, as inquietações e desconfortos, por exemplo, que podem ser gerados com a inserção num espaço tal como o que adentramos, não devem ser tomadas simplesmente como falhas, mas como dados, que refletem muito do funcionamento e dinâmicas estabelecidas e reproduzidas. A flexibilidade do método, como discorre May (2004), é uma vantagem considerável, permitindo uma fluidez nas relações entre o pesquisador e os sujeitos envolvidos, sendo a observação participante um trabalho contínuo e imprevisível, que permite alterações e adaptações.

A observação participante é um instrumento que garante liberdade para que o pesquisador possa apreender as normas vigentes no espaço, bem como observar as contradições das relações desenvolvidas pelos sujeitos, pautando-se na criatividade do pesquisador ao se relacionar com os sujeitos envolvidos e quais afetos serão produzidos nessas relações. Segundo Goldenberg (2004), é frequente o surgimento, ao longo do desenvolvimento da pesquisa, de novas questões que não foram anteriormente previstas, porém que se apresentam de extrema relevância, de modo que "O pesquisador deve estar preparado para lidar com uma grande variedade de problemas teóricos e com descobertas inesperadas, e, também, para reorientar seu estudo" (GOLDENBERG, 2004, p. 28).

Nessa etapa da pesquisa, cada membro da equipe redigiu um diário (ou caderno) de campo, contendo informações, impressões e afetos sobre cada dia de observação. Esse instrumento serviu como forma de descrever não apenas registros pontuais e objetivos da observação, mas a descrição do espaço e sua significação, análise das pessoas que o compunham, a maneira como nossos corpos eram lidos e inseridos naquele espaço por parte dos policiais, técnicos administrativos e adolescentes acautelados. Passamos também a registrar nossas inquietações prévias, durante e pós-observação. Passamos de meros observadores para agentes inseridos no processo observado.

É necessário assinalar que referida ação se deu, em alguns momentos, sob a marca de certa hostilidade por parte da equipe de policiais. Relatamos, por exemplo, o ocorrido que segue. O ofício de permissão da observação na Inspetoria, 
autorizado pela Delegada-Chefe, tinha prazo de 30 dias, de modo que nas últimas semanas da pesquisa o prazo havia vencido. Tal fato foi mal recebido pelos policiais, que em diversos dias da última semana de observação questionaram nossa presença na Inspetoria:

um dos policiais, o mesmo que estava na sexta passada, me pergunta o nome e diz: -"B, até que dia cês ficam aqui?" - "Tenho que confirmar com a minha orientadora, mas no máximo até semana que vem", eu respondo. "É? Por que tá aqui 30 dias... que calendário cês usam? Porque era pra vocês terem parado de vir tem quase um mês" nisso ele me mostra o ofício que enviamos, com o quadro de horário e prazo, que ele imprimiu na impressora (que emperrou enquanto imprimia justo esse papel, que saiu todo rasgado e amassado). Ele ainda diz "se vocês virem mais dia tem que falar e mandar outro pedido pra delegada". Toda a situação foi intimidadora, com um clima de grande desconfiança?

Em nosso último dia de campo, uma assessora da delegada-geral chegou a nos indagar:

"Vocês não ficariam aqui só um mês?". Senti como se já fosse de conhecimento geral entre eles que nós não deveríamos estar lá, uma mensagem oportunamente divulgada, ao passo que nossa autorização para pesquisa nas primeiras semanas era sempre contestada sob a justificativa de que ninguém os tinha avisado disso). ${ }^{2}$

O método da observação participante, por mais importante e eficaz que seja na compreensão de relações específicas, não se mostrou suficiente para apreendermos, de maneira aprofundada, as dinâmicas e tensionamentos ligados à

\footnotetext{
1 Trecho extraído de caderno de campo, dia 06/08/18.

2 Trecho extraído de caderno de campo, dia 09/08/18.
} 
sexualidade e ao gênero no CIA-BH. Dessa forma, a realização de entrevistas individuais semi-estruturadas se fez necessária para complementar a observação participante. O uso combinado de diferentes procedimentos, sobretudo as entrevistas, é constante nas pesquisas qualitativas, pois que, para além de complementar o arcabouço de dados coletados, propicia a triangulação metodológica necessária para sua verificação (GUSTIN, DIAS \& NICÁCIO, 2020). A utilização de observação participante e entrevistas permitiu não só compreender aspectos dos processos normalizadores de gênero nas construções das subjetividades, mas também analisar as relações entre sujeitos de uma Inspetoria da Polícia Civil, uma vez que, pela teoria queer, que é o marco com que se trabalha neste trabalho, as experiências constituem o sujeito. "Assim, elas criam sujeitos marcados por processos sociais que precisam ser reconstituídos, explicitados e analisados pelo pesquisador" (MISKOLCl, 2009, p. 174).

Os dados produzidos nas entrevistas foram importantes para "o desenvolvimento e a compreensão das relações entre os atores sociais e sua situação. O objetivo é uma compreensão detalhada das crenças, atitudes, valores e motivação, em relação aos comportamentos das pessoas em contextos sociais específicos" (GASKELL, 2002, p. 65). Desse modo, a combinação de entrevistas e observação participante possui um grande potencial para a compreensão de espaços/tempos/sujeitos específicos. Sobre as entrevistas, assim se manifesta Duarte:

Nesse caso, se forem bem realizadas, elas permitirão ao pesquisador fazer uma espécie de mergulho em profundidade, coletando indícios dos modos como cada um daqueles sujeitos percebe e significa sua realidade e levantando informações consistentes que the permitam descrever e compreender a lógica que preside as relações que se estabelecem no interior daquele grupo, o que, em geral, é mais difícil obter com outros instrumentos de coleta de dados. (DUARTE, 2004, p. 215) 
Para a condução das entrevistas, utilizamos um tópico guia, instrumento vital ao processo, que direciona a entrevista com os fins de atingir o objetivo da pesquisa. Segundo Gaskell (2002), ele abarca questões teóricas e metodológicas utilizadas como marcos referenciais, reconhecimento prévio sobre o campo e discussões com colegas. Seu uso é consultivo, sendo utilizado para guiar e monitorar o entrevistador ao longo da entrevista, sendo assim, não contém perguntas extensas ou específicas (GASKELL, 2002). O tópico guia é utilizado para direcionar a entrevista de modo fluido, numa progressão lógica e condizente com o desenvolvimento da pesquisa. Sendo um guia, portanto, esse documento não deve engessar a condução da técnica de entrevista.

$\mathrm{Na}$ pesquisa em questão, as entrevistas foram realizadas individualmente com os trabalhadores das instituições com os quais tivemos contato durante as observações participantes. Entrevistamos no total 6 servidores e optamos por selecionar 2 policiais de cada função exercida no edifício que possuíssem contato direto com os jovens, quais sejam. As entrevistas foram realizadas no próprio espaço em que as observações ocorreram, autorizadas via Termo de Concordância por Delegado-Geral, e consentidas pelos participantes via Termo de Consentimento Livre e Esclarecido (TCLE). Cabe, por fim, salientar aqui que, como nossa saída da Polícia Civil no momento das observações participantes havia ocorrido de modo hostil ${ }^{3}$, optamos por aguardar algumas semanas para retomar o contato com os policiais para a realização das entrevistas.

Porém, ao contrário do desejado, nosso primeiro contato de retorno com a Polícia Civil foi igualmente hostil. A retomada dos pesquisadores para a pesquisa foi vista com desconfiança pelo delegado plantonista, responsável pela equipe de policiais da Polícia Civil do prédio, apesar de autorização prévia [do servidor ocupante do cargo de Delegado-Chefe da localidade]: "Nossa conversa com ele foi difícil. Primeiro, ele perguntou o que queríamos. Explicamos que estivemos em campo e voltamos para dar prosseguimento à pesquisa pela entrevista, que seria

\footnotetext{
3 Essa hostilidade, diga-se, é um aspecto amplamente apresentado em pesquisas que se debruçam sobre os mesmos temas, cenários agentes. A título de exemplo, cf. LAMOUNIER, 2018.
} 
voluntária. Ele quis saber o teor das perguntas, sob a justificativa de situar os agentes para quando fosse os convidar para as entrevistas. ${ }^{4}$ Apesar disso, não houve controle direto sobre o conteúdo que seria abordado por nós nessas entrevistas para além dessas especulações e desconfianças, que também foram divididas pelos entrevistados no momento de suas entrevistas.

\section{RESTITUIÇÃO DE CAMPO: ANÁLISES E REFLEXÕES}

A permanência em campo ensejou uma série de reflexões por parte da equipe. Em conjunto, tais reflexões representam o principal produto da investigação empreendida. Tentaremos explicitá-las na presente seção, na qual damos a conhecer a relação dos profissionais e da estrutura envolvidos nas atividades da Polícia Civil com questões atinentes a gênero e sexualidade naquele campo.

Nesse sentido, o primeiro aspecto que releva considerar é que a presença e o uso de armas de fogo (bem como objetos que lhes fazem alusão) são recorrentes. Constatamos que grande parte dos investigadores portam armas de fogo durante o serviço, não raro junto a um distintivo da polícia pendurado no pescoço, ainda que, pelo que foi observado e relatado a nós, nunca terem precisado utilizá-las. Em uma conversa com uma investigadora, ao ser indagada sobre o porte de arma dentro do prédio, "[...] ela [investigadora em serviço] pega na arma por cima da roupa, na cintura, e diz que custou a conseguir [o porte e a arma], que não vai ser agora que ela vai perder a arma"s.

Em um primeiro momento, então, as armas parecem ser usadas como tecnologias para (re)afirmar uma virilidade entre os policiais. Para Hirata (1995, p.42), "a virilidade é associada ao trabalho pesado, penoso, sujo, insalubre, algumas vezes perigoso, trabalho que requer coragem e determinação, enquanto a feminilidade é associada ao trabalho leve, fácil, limpo, que exige paciência e minúcia". No que

\footnotetext{
${ }^{4}$ Relato de entrevista feita em 29/10/18.

5 Trecho extraído de caderno de campo, dia 16/07/18.
} 
toca o trabalho policial é notório a presença de uma cultura permeada por atributos hegemônicos no que toca a masculinidade, tais como a força, coragem, capacidade de decisão - não "se enquadrando nos atributos supostamente 'femininos'" (SACRAMENTO, 2007, p.10).

Via de regra, os policiais carregam a arma dentro de um suporte para que não fique em contato direto com a pele. As mulheres "colocavam a arma no lado e os homens todos colocavam na frente, na altura do pênis", como se, no movimento de sacarem-na e guardarem naquela posição, houvesse um acréscimo de masculinidade sobre suas ações. Ainda, o coldre completo (o suporte junto a uma faixa para prendê-lo ao corpo) é pouco utilizado, já que torna a estética menos rústica e, pelo seu design, não permite acoplar a arma junto ao pênis, apenas na lateral do corpo.

Essa construção associativa entre armas e o universo do masculino é ainda mais reforçada por uma cena presenciada por ocasião das observações: "[...] em certo momento, uma Policial Militar apareceu no salão segurando duas armas grandes. Outro Policial Militar imediatamente surgiu e foi Ihe oferecer ajuda para segurar as armas, ao que ela disse "pode deixar". Ele pegou uma, e ela disse que a outra ela segurava. No fim, ele pegou a outra também e ficou segurando ambas".7 Aqui, mesmo uma policial militar, cuja manipulação do armamento é diária, parece ter sua capacidade e preparo para segurar sua arma diminuída em favor da "cortesia" masculina oferecida pelo suposto verdadeiro detentor da força e do poder - na cena.

Quando havia alguma apreensão de armamento nas ocorrências, os policiais demonstravam grande curiosidade com as armas caseiras, manuseando-as e conversando entre si para compreender o funcionamento delas. O encantamento em torno do objeto logo volvia à associação com o poder, e mesmo as armas apreendidas eram utilizadas para a função intimidatória que ali cumpriam: em certa ocasião, diante de uma apreensão, uma agente

\footnotetext{
${ }^{6}$ Trecho extraído de caderno de campo, dia 09/08/18.

7 Trecho extraído de caderno de campo, dia 19/07/18.
} 
analisa [a arma] e aponta para o adolescente que está sendo autuado. M. (pesquisadora) e eu nos olhamos assustados, a presença de uma arma apontada para alguém é algo que nos traz certo receio. Os outros policiais que ali estavam começam a rir e recomendam à agente para baixar aquilo, uma vez que já está prestes a se aposentar e pode ter problemas. ${ }^{8}$ Em seguida, [...] a arma apreendida foi deixada em cima da mesa, apontando em direção ao rapaz enquanto ele fornecia seus dados [para cadastro no sistema da polícia]. ${ }^{9}$

Somada à afirmação da masculinidade e do poder pelas armas, pudemos verificar que outro modo dos profissionais manterem controle e subjugar os adolescentes simbolicamente é valendo-se da discricionariedade nos procedimentos internos da instituição, um dos elementos mais marcantes observados durante o trabalho de campo. Não foi possível verificar um padrão de trabalho e procedimentos comuns em relação aos adolescentes acautelados. A variação do tratamento dos policiais aos jovens era notável entre equipes e plantões, e em alguns casos a variação ocorria inclusive dentro da própria equipe. A cada mudança de turno podíamos verificar uma forte diferença no tratamento dado aos jovens, que se fez evidente logo nas primeiras observações, a partir de relatos e vivências no campo que eram muito distintas entre os membros da equipe pesquisadora.

Pedidos frequentes, como a ida ao banheiro e ingestão de água, assim como a alimentação e uso de remédios, estes menos comuns, ficam a critério do policial em serviço, são eles que decidem se permitirão que o adolescente tenha acesso a algum desses quatro elementos. Ao longo do trabalho de campo, nos deparamos com situações em que o adolescente pedia diversas vezes para ir ao banheiro e não era atendido, enquanto outros pediam somente uma vez e eram levados. Pudemos ver adolescentes pedindo água e podendo tomar a água do filtro dos próprios

\footnotetext{
8 Trecho extraído de caderno de campo, dia 19/07/18.

9 Trecho extraído de caderno de campo, dia 19/07/18.
} 
policiais, enquanto outros deveriam ir ao bebedouro e outros recebiam orientação para esperar e nunca eram levados para tomar água.

Ressalta-se que a justificativa dada pelos agentes frequentemente volvia na construção de uma relação entre o exercício dessa discricionariedade e a preservação da segurança no ambiente. Assim, a opção por atender ou não uma solicitação, realizar ou não um procedimento ou mesmo pela forma de interação com outros corpos ali presentes serviam ao fim da preservação da segurança. Outrossim, a análise da ação a ser tomada quando do exercício da discricionariedade ora pendia à preservação da segurança da perspectiva da proteção dos corpos aos quais a medida se direcionaria, ora da perspectiva da ameaça, como se tomassem certos corpos como potencialmente disruptivos neste caso, a discricionariedade se exterioriza "por linhas discursivas e práticas bastante duras, que buscam docilizar corpos e subjetividades" (D'ANGELO, HERNÁNDEZ \& UZIEL, 2019, p. 24).

A revista e recolha de objetos pessoais dos jovens também fica a critério do policial em questão, de seu humor, do turno, e, dialogando com a ideia de preservação da segurança acima construída, esse voluntarismo sempre se articula em diferentes níveis com considerações sobre raça, classe, idade, orientação sexual e tipo de infração atribuída ao adolescente. Foram observados momentos em que os adolescentes podiam continuar com seus objetos pessoais enquanto aguardavam na sala da Inspetoria, enquanto em outros momentos eram obrigados a retirar alguns ou todos os pertences e deixá-los em um local específico, longe de seu alcance e à vista da equipe policial. Houve ainda momentos bastante violentos de revistas, cuja condução se diferenciavam das já observadas (que, por si, já não eram uniformizadas), o que reforça o caráter discricionário da prática profissional. "Chega um outro rapaz, preso por tráfico [...], pedem seu nome e, quando ele vai se sentar, um dos policiais pede para ele abaixar as calças e ficar só de cueca para ver se ele não portava nada mais. Foi bastante constrangedor para nós, mas para o menino deve ter sido muito pior". ${ }^{10}$

\footnotetext{
10 Trecho extraído de caderno de campo, dia 06/08/18.
} 
Diante dessas disparidades, em certa ocasião, um de nós perguntou a um inspetor a razão pela qual ele pedia aos adolescentes que sempre levantassem a camisa e se postassem de frente e de costas para fins de revista. $O$ agente respondeu que esse era o procedimento padrão para verificar possíveis objetos escondidos. Entretanto, mesmo no seu turno, foi observado que ele era o único a proceder daquela maneira.

No entanto, como dito, apesar de aparente aleatoriedade para tratamento dos adolescentes, é possível constatar no plano geral uma marcante diferenciação no tratamento dado a adolescentes do sexo feminino e masculino, distinção essa sempre atravessada por questões de sexualidade e raça, vez que, como bem nos lembra Gomes (2019), podemos - e devemos - tomar o gênero como uma categoria de análise decolonial, no qual gênero e raça produzem e se reproduzem de maneira recíproca e dialética. Não é possível, portanto, ter uma visão sobre gênero sem compreender a raça, bem como ter uma visão da raça sem compreender o gênero."

A começar por raça, ressalta-se que, muito embora o objeto principal da pesquisa realizada que é aqui relatada seja compreender como as normas de gênero e a heteronormatividade impactam no acautelamento e regulação dos corpos de jovens em autores de ato infracional, mesmo nesta seara é preciso "a compreensão da construção dos estereótipos de criminosos no contexto nacional, o que, inevitavelmente, deve ter em conta a dimensão racial desses, bem como a forma de funcionamento e atuação das agências executivas" (SOUZA, 2016). Não por acaso, a grande maioria dos adolescentes observados tinham cor negra, vez que a seletividade racial do sistema penal de justiça é refletida e reproduzida no sistema de justiça juvenil.

Os homens, que são maioria entre os adolescentes que ali perpassam, são tratados com mais rispidez - alguns chegaram a passar por episódios de revistas bastante violentos, como já explicitado acima12; não têm liberdade para se

11 Ressalta-se igualmente a importância de outras variáveis para compor uma análise tendencialmente mais holística e interseccional de situações de discriminação múltipla.

${ }^{12}$ Ainda, em outra observação, durante a revista de um adolescente, os policiais "...] pediram que ele tirasse a blusa, levantasse a camisa, subisse as calças até a coxa, revirasse os bolsos para fora e apertasse o saco. Este último pedido foi negado pelo rapaz, constrangido, ao que o policial 
expressar e costumam ser reprimidos constantemente, seja por falarem, seja por quererem trocar de lugar ou por fazerem alguma pergunta aos policiais. Normalmente as mulheres podem se expressar com maior liberdade e têm seus pedidos acatados com maior frequência por parte dos policiais, o que não significa que não haja resistência. No que diz respeito a pedidos de adolescentes trans ${ }^{13}$, em conversas e durante as entrevistas, os policiais demonstraram que não existe nenhum tipo de protocolo sobre qual banheiro utilizar: [...] perguntei sobre a ida ao banheiro das travestis. Alegou não saber como proceder, já que ele nunca levou, por isso não sabe como funciona. Perguntou para outro policial na sala como proceder, este afirmou que leva no banheiro de pessoas com deficiência, porque não há um procedimento padrão. ${ }^{14}$

Foi possível notar uma série de situações em que as diversas experiências dissidentes de gênero e sexualidade não eram reconhecidas e assumidas pelo sistema de justiça da infância e juventude como existentes, seja pela falta de informação [...] o policial comenta que de vez em quando aparecem alguns afeminados ('falo assim porque não vou falar que o cara é viado né')", ou pelo preconceito existente.

Entre os adolescentes, há indícios de situações discriminatórias de vários níveis, que, inclusive, colocam em xeque a atuação dos policiais, mormente inertes diante dessa problemática. Aqui, vemos prevalecer, como resposta a situações de tensão ao que constitui a heteronormatividade social, a reafirmação destas normas, o que implica que

[...] muitas vezes certos direitos fundamentais e, em especial, sua concretização no âmbito da sexualidade, são restringidos ao máximo,

novamente o ordenou, sob justificativa de que ele poderia ter alguma arma ali e assim aparentemente ele ia descobrir. O rapaz obedeceu" (Trecho extraído de caderno de campo, dia 09/08/1).

${ }_{13}$ A expressão "trans" é utilizada em referência a adolescentes que reivindicam uma experiência e reconhecimento de gênero diverso do que foi atribuído no momento do nascimento.

${ }_{14}$ Relato de entrevista feito em 25/10/18.

15 Trecho extraído de caderno de campo, dia 28/06/18. 
quando não, na prática, intencionalmente omitidos ou inconscientemente desapercebidos (...). A liberdade sexual e não discriminação por orientação sexual e por identidade de gênero são situações particularmente aflitivas para crianças e adolescentes, em cuja presença a rejeição da titularidade desses direitos é recorrente. (RIOS, 2013, apud CUNHA; VIDAL, 2015, p. 4)

Assim, por exemplo, no que tange ao preenchimento do nome social ou orientação sexual no Registro de evento de defesa social, observamos que são campos que não são perguntados aos adolescentes, apesar da Resolução SESP $N^{\circ} 18$, de 25 de abril de $2018-^{16}$, que dispõe sobre o assunto. Há inclusive uma grande negligência por parte dos policiais civis em relação ao nome social: em uma entrevista com um policial civil, ao ser indagado sobre nome social, ele não só nega a possibilidade e o direito ao uso do nome social a trans e travestis no espaço, como também ridiculariza a questão. Desse modo, o policial trata o direito ao nome social como mais uma burocracia ao ofício policial, que retardaria e dificultaria seu trabalho. Ainda, o policial desconsidera e desconhece que o nome social possui caráter legal.

Já outro policial entrevistado, de mesmo cargo (escrivão), relata que sim, o nome social é um direito que é respeitado pelos policiais. Entretanto, a discrepância na fala dos policiais sobre o nome social expõe novamente a discricionariedade da atuação profissional. O nome social não é encarado como um direito dos jovens: fica a cargo do policial em questão de permitir que jovens travestis e transexuais sejam tratados pelo nome social. As divergências nas narrativas dos policiais aparecem em diversas entrevistas. Em algumas, nega-se a possibilidade do nome social, enquanto em outras, afirma-se o nome social enquanto um direito. Muitas

\footnotetext{
${ }^{16}$ A Resolução SESP N 18 , de 25 de abril de 2018, estabelece diretrizes e normativas para o atendimento e tratamento da pessoa LGBT no âmbito do Sistema Socioeducativo do Estado de Minas Gerais. Dentre as diretrizes estão a observância ao princípio de autodeterminação dos adolescentes, o respeito ao nome social, a possibilidade de vestimenta em consonância com o gênero reivindicado, dentre outras. Disponível em: http://www.seguranca.mg.gov.br/images/2018/ABRIL/Resolu\%C3\%A7\%C3\%A3O_SESP_n\%C2\%BA_18. pdf. Acesso: nov. 2019.
} 
vezes, ainda, há desinformação por parte dos policiais sobre a possibilidade do nome social, bem como seu valor legal.

Reforça-se, pois, a partir da discricionariedade da atuação policial, o apagamento da identidade de transexuais e transgêneros, o que importa em invisibilização e violência simbólica de autoria pelo próprio Estado, que seria em tese garantidor de direitos. Subjaz a esta atuação "a ideia da necessidade da classificação social fixa e binária e da obsessão pelas identidades sexuais, como impulsionadas pelas disciplinas e também pelo controle" (JUNIOR, 2016, p. 175).

Ademais, ressalta-se que um dos fatores ligados à construção de essencialismos que por vezes fundamentam 0 trato discriminatório dos adolescentes no sistema é o modo com que os policiais, de modo geral, encaram os atos infracionais cometidos por adolescentes do sexo masculino e feminino. Alguns policiais confirmam e reafirmam tal diferença, identificando, por exemplo, diferente "natureza" do ato infracional cometido entre meninos e meninas ali: Em geral, há mais meninos nas ocorrências, e se relacionam a tráfico, roubo e furto. As meninas praticam mais furto. ${ }^{17}$

Em diversas entrevistas, os policiais não só identificaram diferenças na natureza dos atos infracionais cometidos por meninas e meninos, mas também Ihes atribuíram uma causa. Essa causa parece ser delimitada mais por diferentes visões e entendimentos que os próprios policiais têm sobre o que é próprio de cada gênero do que por observações práticas do ofício. Durante uma entrevista com um investigador da polícia civil, foi afirmado que as diferenças na natureza do "delito" [termo usado pelo policial] de homens e mulheres se deve ao fato da mulher ser mais caseira mais sossegada mais família, o homem vai mais pra vida do crime, é mais vulnerável, vai mais pra rua que a menina. ${ }^{18}$ Porém, nem todos os policiais relataram identificar diferenças, seja na natureza do delito ou seja nas motivações, entre meninos e meninas. Ao perguntar se há diferença da natureza do delito, ele

\footnotetext{
${ }^{17}$ Relato de entrevista feito em 19/10/18.

${ }^{18}$ Relato de entrevista feito em 25/10/18.
} 
nega, dizendo que "É tudo tráfico, roubo e furto" e que o modo de os atender é o mesmo, pois "São todos delinquentes, o procedimento é todo igual".

Percebemos que essa construção está pautada numa visão de corpos femininos enquanto dóceis, vulneráveis e assujeitados, o que, dentro da criminologia feminista, é apontado como causa de fenômenos de vitimização e criminalização que incidem peculiarmente sobre as mulheres. ${ }^{19}$ Consonantemente, quando autoras de ato infracional a reação e a narrativa de justificação que se constrói pelo sistema de justiça será uma para infrações que são tidas por "femininas", enquanto as infrações por condutas atribuídas ao próprio do masculino têm peso de uma dupla transgressão com consequências outras, por conta da adicional insubordinação ao papel social que é esperado conformar-se a mulher (CASSOL, SILVA \& DINARTE, 2018).

Diferenças na natureza do ato infracional cometido também são observadas por alguns policiais em relação a jovens dissidentes de gênero e sexualidade, enquanto outros não notaram diferenças substanciais, afirmando que o padrão do ato infracional de uma "menina masculina" é o mesmo que dos meninos ${ }^{20}$. Aqueles que observavam essa diferença, ressaltaram que tais jovens se envolvem mais em casos de furto, roubo e briga, apesar de também se envolverem com tráfico: Tanto menina quanto menino homossexual normalmente é roubo, furto e tráfico. ${ }^{27}$ Quanto às travestis[...] os atos infracionais geralmente são tráfico, furto e roubo ${ }^{22}$, ou briga, menos frequentemente. Vemos, portanto, que adolescentes dissidentes de gênero e sexualidade são identificados pelos agentes como potenciais infratores de delitos de mesma natureza dos homens cis heteronormativos, o que corroboraria, remetendo novamente à ideia de segurança, à justificativa de maior necessidade de controle (com o viés da ameaça) aos seus corpos.

\footnotetext{
19 Sobre os tensionamentos entre as narrativas de vitimização e criminalização de mulheres autoras de ato infracional, cf., a título de exemplo, BARCINKI, CÚNICO, 2016; D'ANGELO, 2017.

${ }^{20}$ Relato de entrevista feito em 27/10/18.

${ }^{21}$ Relato de entrevista feito em 21/10/18.

22 Relato de entrevista feito em 27/10/18.
} 
Por fim, releva considerar como as categorias de gênero e sexualidade incidem nas dinâmicas dos policiais entre si, bem como na relação dos pesquisadores com o campo, vez que o enfoque no impacto de nossos corpos e nossas experiências na observação são dados importantes para a metodologia adotada. Vale lembrar que, como já discutimos aqui, na observação participante, o pesquisador é um sujeito ativo cuja presença modula e interfere ativa e constantemente no campo ao mesmo tempo em que ele mesmo é afetado por ele.

A começar pelos policiais, foi possível notar em que moldes a distinção e organização de tarefas a serem executadas internamente nas equipes se dão. Essa distinção parece ser fortemente marcada pela forma com que se produz gênero naqueles espaços. Há tarefas que, usualmente, são exercidas por alguma policial no plantão, como por exemplo (e talvez seja a que demonstre isso de forma mais patente) a feitura de café: [...] todas as vezes que os presenciei fazendo o café era a moça da faxina, à exceção do primeiro dia em campo ${ }^{23}$. A divisão da feitura do café é tão forte que certo turno em que não havia nenhuma mulher presente, por conta de diligências externas, e os homens queriam tomar café, ao invés de o fazerem, optaram por ir até a padaria comprá-lo pronto ${ }^{24}$.

Além disso, outra tarefa fortemente marcada pela divisão de gênero é atender ao telefone. Quando há uma policial na equipe no momento em que o telefone da Inspetoria toca, parece já haver um acordo implícito de que é sua função atender. O telefone toca e ninguém se move. A única policial mulher é quem atende. Parece que as policiais mulheres que são encarregadas dessa função. ${ }^{25}$ As tarefas que exigem menor esforço físico e/ou que causam maior sensação de poder e controle sobre os adolescentes normalmente são realizadas pelos policiais homens.

Ainda, aproveitando as conversas informais, que são frequentes, dada a intimidade que nutrem pelo convívio, podem-se observar várias situações para reflexão. A começar pelos tópicos, parece haver assuntos preferenciais que

\footnotetext{
23 Trecho extraído de caderno de campo, dia 05/07/18.

24 Trecho extraído de caderno de campo, dia 16/07/18.

25 Trecho extraído de caderno de campo, dia 06/08/18.
} 
polarizam os participantes: os policiais conversam entre si sobre diversos assuntos, como imposto de renda, acupuntura e massagem (as policiais mulheres) e cortes e modo de preparo de carnes (os policiais homens) ${ }^{26}$.

Além disso, foi possível apreender, dessas conversas, situações de efetivo assédio enfrentadas pelas profissionais na realização de suas tarefas, relatadas por elas com naturalidade. De outro modo, quando as conversas envolviam apenas homens que pareciam aderir a padrões heteronormativos de comportamento, a comparação com o feminino era artifício para fazer chacota, diminuir a virilidade do destinatário da fala.

Já no que toca aos pesquisadores, um aspecto importante que percebemos ao longo do tempo em campo foi o efeito que nossos corpos, pesquisadores e pesquisadoras, causavam nas dependências da delegacia. Tais efeitos, por sua vez, eram permeados por questões de gênero e sexualidade que apontavam na direção das reflexões que acumulávamos em campo. A experiência no campo se diferia bastante entre as pesquisadoras e os pesquisadores. Em determinado dia, " $X^{27}$ [inspetor], assim que D [pesquisador] saiu para lanchar, se aproximou de mim [pesquisadora]. "Posso me sentar?" e sentou-se de frente pra mim [...]. Enquanto falava, ele se aproximava de mim (a cadeira era daquelas de rodinha, fáceis de mover). Lembro de ir um pouco pra trás sempre que sentia ele mais perto, até que cheguei ao limite do armário oposto às minhas costas. Seus gestos pareciam cada vez mais expansivos, ao ponto de suas mãos começarem a passar rentes a minha perna. Assim que o $D$ voltou, ele se levantou e permaneceu o resto do dia afastado."128

O corpo dos pesquisadores no espaço também foi pautado pela performance de gênero, e nas masculinidades de cada pesquisador. Entre os pesquisadores que performam um gênero masculino, os policiais conversavam e interagiam mais, se comparado à interação com pesquisadores que eram

\footnotetext{
${ }^{26}$ Trecho extraído de caderno de campo, dia 16/07/18.

${ }^{27}$ Todos os nomes contidos nos diários de campo foram omitidos e substituídos por letra alfabética de atribuição aleatória.

${ }^{28}$ Trecho extraído de caderno de campo, dia 27/06/18.
} 
considerados como mais afeminados. Sinto que de certa forma os policiais não se sentem muito à vontade comigo, exatamente por eu não condizer com a expectativa masculina do ambiente, e eu também não me sinto à vontade perto deles. $^{29}$

Quando as duplas de pesquisadores em campo correspondiam a dois sujeitos não heteronormativos, o estranhamento com a equipe policial era presente: A principal impressão que tive foi de que a presença minha e do $B$, de nossas corporalidades e performances não eram bem vistas pelos policiais homens. Tanto eu como $B$ temos comportamentos e aparências que são normalmente identificadas como de "bichas". A maneira que sentamos, conversamos, nos vestimos, e vários outros significantes foram percebidos como "não pertencentes" àquele lugar, às vezes vigiladas, e que grande parte do desconforto do delegado que estava no local se deu em função disso.

De forma oposta, quando a dupla se compunha de dois sujeitos com performances mais próximas da normatividade, havia maior interação e, consequentemente, maior conforto dos pesquisadores com o ambiente: [n]ão achei nada muito distinto de um almoço familiar, o que talvez explique porque eu não me senti desconfortável naquele ambiente, ao contrário do que esperava pelo relato [de outros pesquisadores] $]^{30}$.

Essas diferenciações, por certo, afetaram na pesquisa de diferentes formas. Seja em maior ou menor cordialidade e abertura a interações a depender dos pesquisadores em campo, o que afetava na colheita de informações pelo pesquisador a partir de questionamentos diretos; seja na maior ou menor contenção dos agentes em relação aos seus atos, falas e interações no exercício de seus ofícios (inclusive em como conduziam as tratativas junto aos adolescentes) ou em momentos de descontração a depender de seus juízos sobre como estas condutas seriam recepcionadas pelos pesquisadores; ou mesmo no conforto e

\footnotetext{
29 Trecho extraído de caderno de campo, dia 16/07/ 18.

30 Trecho extraído de caderno de campo, dia 28/06/18.
} 
segurança sentidos pelos próprios pesquisadores para conduzir a pesquisa e imergir no campo.

\section{CONSIDERAÇÕES FINAIS}

Em face da natureza primária dos dados encontrados em campo, algumas considerações se impõem tanto em relação ao sistema de justiça juvenil em geral, quanto aos atravessamentos de gênero e sexualidade neste sistema, em particular.

No que toca à interface sistema e questões de gênero e sexualidade, afirmamos que, embora não tenham sido identificados, ao longo do período de realização da pesquisa, adolescentes pertencentes ao público de homossexuais, travestis ou transexuais, vários índices parecem apontar para uma ordenação das relações dentro do espaço observado marcadas pela hierarquização e pela estereotipação, segundo padrões heteronormativos. Entre profissionais do campo e adolescentes autores de ato infracional, a heteronormatividade está presente nos gestos, nas expressões e mesmo nos silêncios observados em campo. Quanto aos possíveis e eventuais adolescentes cuja relação ao gênero e à sexualidade pode ser tida como dissidente ou divergente da norma padrão, tais condutas, sejam as expressas ou apenas sugeridas e silenciadas, podem engendrar medo e ocultamento, posto se tratar de ambiente voltado não somente à socioeducação, segundo a pretensão (ilusoriamente?) inclusiva da Constituição Federal de 1988 e do Estatuto da Criança e do Adolescente ${ }^{31}$, mas também à segurança pública e à repressão. Condutas heteronormativas parecem, assim, se somar a preconceitos e visões de mundo pré-estabelecidas que situam o adolescente e a adolescente que chegam como delinquentes necessários, em que eventuais transgressões ligadas ao "gênero" e à "sexualidade" tendem a se exprimir como uma transgressão a mais - talvez a mais insuportável? - em um percurso marcado pela atuação infracional.

\footnotetext{
${ }^{31}$ Ideal decorrente da Doutrina de Proteção Integral, consubstanciada no artigo 227 da Constituição Federal e objeto principal do Estatuto da Criança e do adolescente, por força de seu artigo $1^{\circ}$.
} 
Por outro lado, no que concerne à relação entre os profissionais atuantes no contexto analisado, merece atenção o fato de que normas de gênero são suscetíveis de reger os menores passos dentro de um ambiente controlado, no qual a hierarquização volta a atuar, agora na performatividade de gênero entre policiais. Obviamente, a interface entre tais relações e aquelas que se observam entre profissionais e adolescentes parece responder a um modo mimético e replicativo, segundo o qual a heteronormatividade deixa pouco espaço para a diversidade, a despeito do que dizem os códigos e as leis.

\section{REFERÊNCIAS}

Barcinski, Mariana; Cúnico, Sabrina Daiana. Mulheres no tráfico de drogas:

Retratos da vitimização e do protagonismo feminino. Civitas, Rev. Ciênc. Soc., Porto Alegre, v. 16, n. 1, p. 59-70, Mar. 2016.

Bento, B (2006). A reinvenção do corpo: sexualidade e gênero na experiência transexual. Rio de Janeiro: Garamond.

Cassol, Paula Dürks; Silva, Maria Beatriz Oliveira da; Dinarte, Priscila Valduga. A vida mera das obscuras: sobre a vitimização e a criminalização da mulher. Rev. Direito Práx., Rio de Janeiro, v. 9, n. 2, p. 810-831, junho, 2018.

Cunha, R. L. C; Vidal, J. S. Medidas socioeducativas e adolescentes trans: dos impasses institucionais ao reconhecimento de direitos. Texto apresentado quando do IV ENADIR, USP, 25 a 28 de agosto de 2015.

Duarte, R (2004). Entrevistas em pesquisas qualitativas. Educ. rev., Curitiba, n. 24, 213-225.

D’Angelo, Luisa Bertrami. Entre "sujeita-mulher" e "mulher de bandido": produções de feminilidades em contexto de privação de liberdade. 
Dissertação (Mestrado em Psicologia Social) - Programa de Pós-Graduação em Psicologia Social, Universidade do Estado do Rio de Janeiro, Rio de Janeiro, 2017.

D’Angelo, Luisa Bertrami; Hernández, Jimena de Garay; Uziel, Anna Paula. Por entre fronteiras e dobras da prisão: traçando cartografias em ethos feminista. Cadernos Pagu (55), 2019, p. 1-30.

Gaskell, G (2002). Entrevistas individuais e grupais. In: BAUER, MW. GASKELL, G. (org.). Pesquisa qualitativa com texto, imagem e som: um manual prático (p. 64-90). Petrópolis: Vozes.

Goldenberg, M (2004). A arte de pesquisar. 8a ed. Rio de Janeiro: Record.

Gomes, C. M. Gênero como categoria de análise decolonial. Civitas, Rev. Ciênc. Soc., Porto Alegre, v. 18, n. 1, p. 65-82, Apr. 2018.

Gustin, Miracy B. S.; Dias, Maria Tereza F.; Nicácio, Camila S. (2020). (Re) pensando a pesquisa jurídica. São Paulo: Almedina.

Hirata, H (1995). Divisão - relações sociais de sexo e do trabalho: contribuição à discussão sobre o conceito de trabalho. Em Aberto, Brasília, MEC/Inpe, v.1, n.65, p.39-49, jan./mar.

Junior, Jonas Alves da Silva. Direitos à meia luz: regulamentação do uso do nome social de estudantes travestis e transexuais nas instituições escolares. Revista da FAEEBA - Educação e Contemporaneidade, Salvador, v. 25, n. 45, p. 173-189, jan./abr. 2016.

Lamounier, Gabriela Almeida Moreira. Gêneros encarcerados: uma análise trans.viada da política de Alas LGBT no Sistema Prisional de Minas Gerais. 
Dissertação (Mestrado em Psicologia) - Programa de Pós-Graduação em

Psicologia, Universidade Federal de Minas Gerais, Belo Horizonte, 8

May, T (2004). Observação Participante: perspectivas e práticas. In: Pesquisa social: questões, métodos e processos. Porto Alegre: Artemed. 2004. 173-2003.

Minayo, Maria Cecília de Souza (2008). Trabalho de campo: contexto de observação, interação e descoberta. In: MINAYO, Maria Cecília de Souza (org.) In: Pesquisa social: teoria, método e criatividade. Petrópolis: Vozes. 2008. p. 61-77.

Miskolci, Richard (2009). A Teoria Queer e a Sociologia: o desafio de uma analítica da normalização. Sociologias, n. 21, v. 337, p. 150-182.

Sacramento, J. S (2007). Polícia e gênero: percepções de delegados e delegadas da Polícia Civil do Rio Grande do Sul acerca da mulher policial. Dissertação (Mestrado em Sociologia), Programa de Pós-Graduação da Universidade Federal do Rio Grande do Sul.

Silva, Gustavo de Melo. Ato Infracional: fluxo do Sistema de Justiça Juvenil em Belo Horizonte. Dissertação (Mestrado em Sociologia) - Programa de PósGraduação em Sociologia, Universidade Federal de Minas Gerais, Belo Horizonte, 2010.

Souza, Thais Diniz Coelho de. Seletividade racial do sistema penal brasileiro: origem, mecanismos de manutenção e sua relação com a vulnerabilidade por culpabilidade. Cadernos do CEAS: Revista crítica de humanidades, n. 238, p. 611-626, dez. 2016 
- FINANCIAMENTO: Este artigo é fruto de pesquisa financiada pela Fundação de Amparo à Pesquisa do Estado de Minas Gerais (FAPEMIG), à qual autoras e autor agradecem o apoio.

'Camila Silva Nicácio: Professora da Faculdade de Direito da UFMG, Coordenadora da Clínica de Direitos Humanos (CdH/UFMG).

iiJúlia Silva Vidal: Mestranda em Direito pela Universidade Federal de Minas Gerais (UFMG), Orientadora da Clínica de Direitos Humanos da UFMG (CdH/UFMG), Pesquisadora do Núcleo de Direitos Humanos e Cidadania LGBT (Nuh/UFMG).

iiiMariana Ferreira da Silva: Graduanda em Direito pela Universidade Federal de Minas Gerais (UFMG), Estagiária da Clínica de Direitos Humanos da UFMG (CdH/UFMG).

ivHugo Ribeiro Lanza: Graduando em psicologia pela Universidade Federal de Minas Gerais (UFMG), Estagiário da Clínica de Direitos Humanos da UFMG (CdH/UFMG).

Data de submissão: 09/11/2019

Data de aprovação: 07/06/2021 